\title{
A randomised controlled trial of probiotics for the prevention of spontaneous preterm delivery associated with bacterial vaginosis: preliminary results
}

Leticia Krauss-Silva ${ }^{1 *}$, Maria Elizabeth L Moreira ${ }^{2}$, Mariane B Alves ${ }^{1,3}$, Alcione Braga ${ }^{4}$, Karla G Camacho ${ }^{1}$, Maria Rosa R Batista ${ }^{5}$, Antonio Almada-Horta ${ }^{6}$, Maria R Rebello ${ }^{1}$ and Fernando Guerra ${ }^{5}$

\begin{abstract}
Background: Bacterial vaginosis increases the risk of spontaneous preterm delivery at less than 34 weeks of gestation.

Objective: The purpose of this study was to evaluate the efficacy of the early administration of selected lactobacilli strains (probiotics) to pregnant women with asymptomatic bacterial vaginosis/intermediate-degree infections to prevent spontaneous premature delivery and associated neonatal morbidity.

Methods/Design: Asymptomatic pregnant women at less than 20 weeks of gestation, with no indication of elective preterm delivery, with a vaginal $\mathrm{pH} \geq 4.5$ and Nugent score $>3$ were randomly assigned to the placebo or intervention group (oral administration of selected lactobacilli up to the 24th to 26th week of gestation). The randomisation was stratified for the history of premature delivery (HPD) and blocked. The allocation was concealed, and the participating health professionals and patients were blinded. The primary outcome was preterm delivery $(<34$ to $<32$ weeks), and the secondary outcomes were associated neonatal complications.

Results: In total, 4,204 pregnant women were screened; 320 and 324 individuals were respectively randomly assigned to the placebo and intervention groups, and $62 \%$ finished the trial. None of the randomised patients were lost to follow-up. For the non-HPD stratum, the intent-to-treat relative risks of spontaneous premature birth at $<34$ and < 37 weeks' gestation were $0.33(0.03,3.16)$ and $0.49(0.17,1.44)$, respectively, and they were nonsignificant (ns) with $p=0.31$ and 0.14 . The corresponding actual treatment figures were zero and $0.32(0.09,1.19)$, which were ns with $p=0.12$ and 0.06 . The intent-to-treat relative risk of spontaneous premature birth at $<37$ weeks of gestation for the trial as a whole, including HPD and non-HPD participants, was $0.69(0.26,1.78), p=0.30$ (ns). The neonatal complications under evaluation occurred in only one infant ( $<34$ weeks; placebo group) who presented with respiratory distress syndrome and suspected early neonatal sepsis. The recorded adverse events were minor and relatively non-specific.
\end{abstract}

Conclusions: The efficacy of the tested probiotics to prevent preterm delivery among women without a history of preterm delivery was not determined because the study sample was insufficient to estimate statistically significant intent-to-treat effects; additional studies are needed to evaluate this intervention among these women.

Trial registration: Trial registration at NIH register: NCT00303082. Sources of funding: the Brazilian Health Ministry and the State of Rio de Janeiro Research Foundation.

\footnotetext{
* Correspondence: leticiak@ensp.fiocruz.br

${ }^{1}$ Health Technology Assessment Unit, National School of Public Health, Oswaldo Cruz Foundation, Brazilian Health Ministry, Brazil, R. Leopoldo Bulhões, 1480, Rio de Janeiro, 21041-210, Brazil

Full list of author information is available at the end of the article
} 
Keywords: spontaneous preterm delivery, prevention, randomised controlled parallel-group trial, probiotics, history of preterm delivery

\section{1- Background}

High rates of preterm delivery, i.e., above $10 \%$, remain prevalent in developing and developed regions around the world; preterm birth is associated with nearly $80 \%$ of foetal, neonatal, and infant deaths [1-3].

Approximately $25 \%$ of preterm deliveries occur as the result of medical indications, and the remaining cases occur spontaneously [4]. Spontaneous preterm deliveries that occur prior to 35 weeks of gestation, and before the $32^{\text {nd }}$ week in particular, have been strongly associated with intrauterine infections, including bacterial vaginosis (BV) $[5,6]$. A history of preterm delivery (HPD) is the most important factor in spontaneous preterm delivery; HPD increases the risk of a subsequent preterm delivery by threefold and is likely associated with underlying risk factors $[4,7,8]$. Important risk factors for spontaneous preterm delivery, such as age $<18$ years, race, education, and bacterial vaginosis, are associated with a low socioeconomic status. BV doubles the risk of preterm delivery prior to 35 weeks of gestation [7]. BV is present in 15$20 \%$ of normal pregnant women in developed countries [7], and this proportion is almost twice as high in highrisk populations [9].

Prematurity resulting from intrauterine infections increases the probability of complications, including early sepsis, bronchopulmonary dysplasia, periventricular leukomalacia, and necrotising enterocolitis [10-13], which may cause long-term neurological disabilities and death.

Bacterial vaginosis (BV) is a modification of the vaginal flora that is characterised by a diminished or absent flora of lactobacilli, which increases the vaginal $\mathrm{pH}$ and leads to a significantly increased colonisation by several anaerobic or facultative microorganisms, including Gardenerella vaginalis, Prevotella sp., Bacteroides sp., Mobiluncus sp., Gram-positive cocci, and genital mycoplasma [14].

The association between infections of the upper genital tract and preterm delivery (premature birth) in BV asymptomatic women formed the basis of several trials using antibiotics to prevent preterm delivery in these women; the results of these trials have been contradictory [15-17]. The results of a very large, well-designed trial did not indicate any clear benefit of antibiotic therapy; in addition, the study showed negative results in the subgroup of patients with a history of preterm delivery [18]. Bacterial resistance, timing of the intervention (possibly delayed), and foetal inflammatory syndrome, which can result in early intrauterine death, could help explain such results [19-21].
The study presented here tested an alternative to antibiotics, i.e., so-called probiotics (a type of bacterial therapy), to prevent preterm delivery associated with intrauterine infections originating from bacterial vaginosis. Probiotics have been tested mainly for treating infectious, inflammatory, and allergic conditions that occur in the intestinal, genitourinary, and respiratory tracts [22-24]. Many of the effects of probiotics are not related solely to changes in the microbiota, as indicated by cultivation experiments; rather, many of the beneficial effects of probiotics are related to their immune-modulating effects (i.e., increases in both immunologic and anti-inflammatory activity) [25]. The rationale for the trial presented here was the manipulation of vaginal microbiota to interrupt the infectious/inflammatory process that leads to preterm delivery.

Four small trials have tested the efficacy and safety of selected probiotics (generally, Lactobacillus rhamnosus GR-1 associated with Lactobacillus fermentum TC-14) for curing urogenital infections, including BV, in asymptomatic non-pregnant women [26-30]. Oral treatments of more than one million of each selected bacillus, administered once or twice daily for 2-8 weeks, showed an efficacy for curing BV (Nugent score) of at least 40\%, which was statistically significant. The best results corresponded to the highest dose regimen; most of the treatment effect remained one month after the end of the treatment. No adverse events were reported. However, there is no evidence of the efficacy of probiotics to prevent BV-related conditions, such as preterm delivery and neonatal morbidity.

\section{General Objectives}

To estimate the efficacy of the early administration of specially formulated probiotics to pregnant women with bacterial vaginosis or intermediate-degree infection to prevent the occurrence of spontaneous premature delivery and related neonatal mortality and morbidity.

\subsection{Specific objectives}

a- To assess the presence of bacterial vaginosis and intermediate-degree infections in asymptomatic pregnant women with no risk/indication of elective preterm delivery who were admitted to prenatal care after the $8^{\text {th }}$ and before the $20^{\text {th }}$ week of gestation.

b- To investigate whether the study intervention can reduce the vaginal $\mathrm{pH}$ and the Nugent score.

c- To assess the efficacy of an early intervention with special probiotics to treat bacterial vaginosis/ 
intermediate-degree infections and to prevent spontaneous preterm delivery and associated neonatal conditions in positive women, according to item $a$, by conducting a controlled, randomised, patient-allocatorphysician/nurse-evaluator-blind trial.

\section{Methodology}

A detailed version of the trial protocol was presented in a previous paper [31].

Asymptomatic pregnant women who were admitted after the $8^{\text {th }}$ and before the $20^{\text {th }}$ week of pregnancy in selected public prenatal services in the city of Rio de Janeiro were evaluated to identify a) excluding clinical conditions associated with elective preterm delivery, symptomatic vaginal conditions, and the recent use of corticotherapy or antibiotic therapy and b) pregnant women with a previous history of preterm delivery.

Gestational age was determined by ultrasound in $71 \%$ of the randomised women; in $29 \%$ of the randomised women, only the date of the last menstrual period was available upon admission to the trial.

Women who tested positive for syphilis, toxoplasmosis, gonorrhoea, or HIV were excluded. Women reporting vaginal discharge were excluded only if a vaginal smear analysis showed bacterial vaginosis, trichomoniasis, or candidiasis; women with macroscopic genital lesions or microscopic pre-cancerous HPV-related lesions were excluded.

The additional exclusion criteria were applied: multiple gestation, cervical incompetence (cerclage in current gestation), and clinical suspicion of a lower urinary tract infection.

After written informed consent was obtained, a vaginal $\mathrm{pH}$ assessment was performed; patients with $\mathrm{pH}<4.5$ were excluded. A cervicovaginal smear was then obtained to evaluate the presence of BV or an intermediate-degree infection using the Nugent method [32]. Women with Nugent scores $<4$ were excluded from the trial.

\section{Randomisation and Blinding}

Randomisation was stratified according to the history of premature delivery (HPD) and blocked.

The sequences for randomisation were electronically generated by an independent research assistant who produced one blocked and randomised list for each stratum using a permuted block design. After written informed consent was obtained, women with Nugent scores $>3$ were randomly assigned to receive capsules of either a placebo or probiotics, which were identical in appearance, in sequentially numbered identical containers according to the allocation sequence. Research nurses responsible for the allocation were not directly involved with prenatal care, i.e., with clinical screening.
Physicians/nurses and researchers/evaluators were also blinded to the randomisation process.

\section{Intervention}

The trial tested two lactobacilli strains, Lactobacillus rhamnosus GR-1 and Lactobacillus reuteri RC-14, that were developed and studied by Reid et al. [26-30]. Each capsule contained more than one million bacilli of each strain. The participants were instructed to take two capsules per day up until approximately the $24^{\text {th }}-26^{\text {th }}$ week of gestation; the treatment duration varied from six to twelve weeks depending on the participant's gestational age at the time of enrolment in the study.

Compliance/adherence, adverse events, and clinical intercurrences were monitored by the research nurse at each routine prenatal visit until the completion of the treatment. Adherence was defined as at least 6 weeks of treatment with ingestion of at least $80 \%$ of the prescribed dose. At the post-treatment prenatal care visit, vaginal $\mathrm{pH}$ was assessed; a cervicovaginal smear and fluid were obtained to the evaluate changes in these parameters.

The primary outcome was spontaneous preterm delivery between 34 and 37 weeks' gestation. Associated morbidities, early neonatal sepsis, respiratory distress syndrome, bronchopulmonary dysplasia, periventricular leukomalacia, necrotising enterocolitis, and retinopathy of prematurity were the secondary outcomes. The definitions of these conditions were similar to those used by the Vermont-Oxford Network [33].

\section{Sample size}

The estimated prematurity rate for deliveries at $<34$ weeks was $6 \%$; the estimated efficacy was $50 \%$. With a $5 \%$ significance level, one- and two-sided tests, and $80 \%$ power to detect differences in the premature birth rates between the intervention and placebo groups, the trial sample size was estimated to be 1,140 and 1,480, respectively.

\section{Results}

\section{Flow of patients}

Figure 1 shows the flow of patients according to the protocol and the latest CONSORT guidelines [34-36]. In total, 4,204 pregnant women were screened for the selected clinical conditions; 1,506 were excluded for one or more of the following conditions: hypertension, diabetes, asthma, cervical incompetence, atypical vaginal bleeding, atypical vaginal secretion, HPV, gonorrhoea, syphilis, dysuria, pruritus, burning, corticotherapy, recent antibiotic therapy (within 8 weeks prior to screening), or other miscellaneous clinical factors. Of the remaining patients, 381 pregnant women were not eligible because their gestational age was 20 weeks or greater; 202 were 


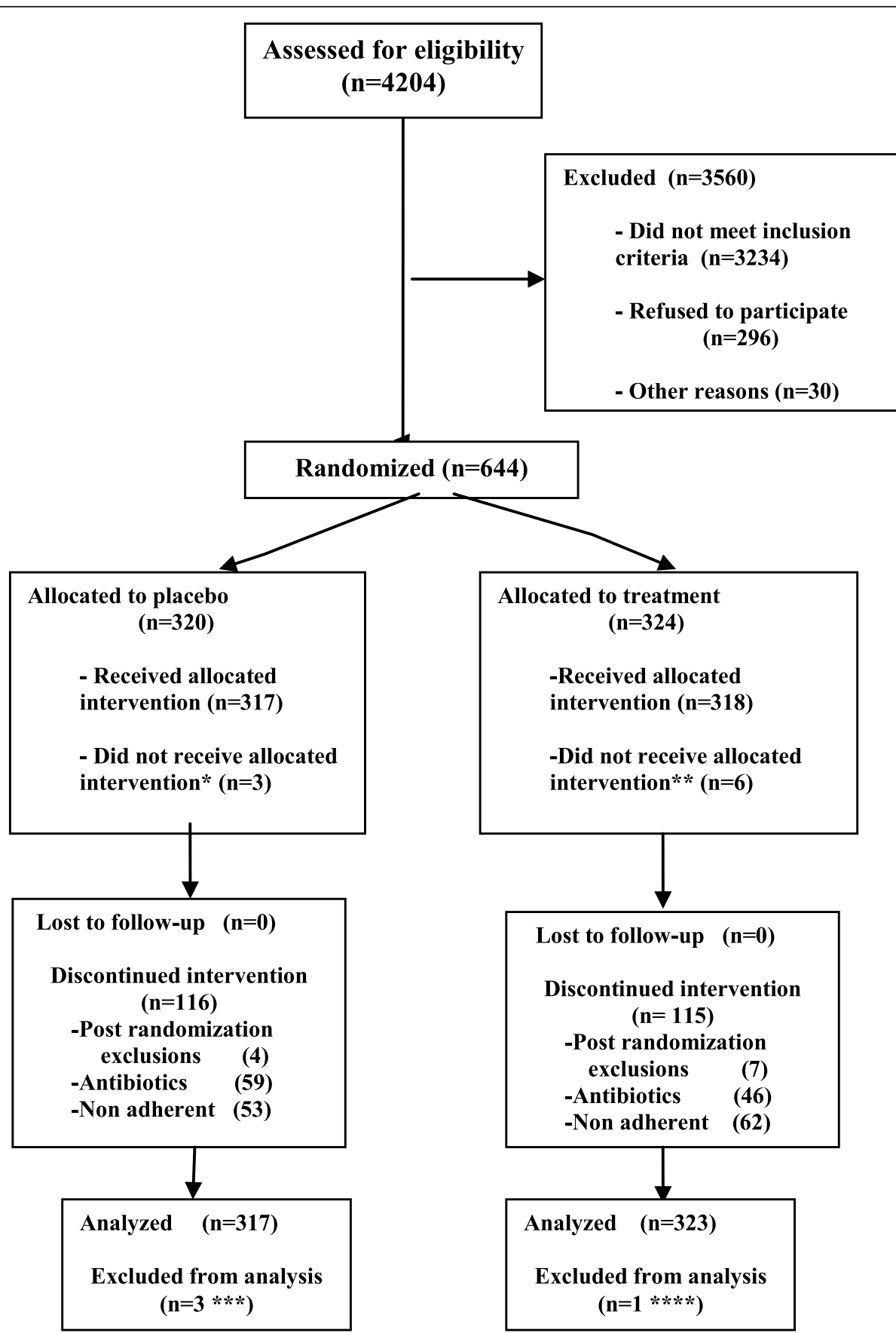

Figure 1 Observed flow of patients in the trial. * Returned all capsules (lack of adherence), unknown reason. ** Returned all capsules (unknown reason) (3), family opposed participation in the trial (1), pregnant woman suffered abortion (1), participant presented with UTI (1); the last two events occurred on the day that they were randomly assigned. ${ }^{* * *}$ Randomisation error (3): Nugent score $<4$ (2); gestational age miscalculation (1). ${ }^{* * * *}$ Randomisation error (1): Nugent score $<4$.

not eligible at the first visit because their gestational age was less than 8 weeks, and they were not available during subsequent prenatal visits; 28 women could not provide the date of their last menstrual period and did not present an ultrasound test; and 233 individuals refused consent for the first phase of the trial.
Vaginal $\mathrm{pH}$ was determined for 1,854 women: 546 had $\mathrm{pH}<4.5$ and were excluded. Of the $\mathrm{pH}$-eligible women, 554 had Nugent scores $<4$ and were excluded. Six women refused consent for the intervention phase of the trial. Of the women who were then eligible for randomisation and provided consent, 104 were not 
randomly assigned because they did not attend the visit or presented with excluding conditions at the prenatal care/randomisation visit (particularly hypertension and symptomatic vaginal infection). Finally, 644 women were randomly assigned, with 324 allocated to the intervention group and 320 placed into the placebo group. Of these women, 9 did not start treatment, 318 initiated treatment with probiotics, and 317 began taking the placebo.

After the initial treatment, 120 women in the placebo group and 122 in the treatment group discontinued the intervention: a) 4 women were excluded from the placebo group (3 women because of pregnancy-induced hypertension and 1 individual was overweight), and 7 were excluded from the treatment group (1 case of umbilical hernia and thrombocytopenia, 4 cases of pregnancy-induced hypertension, 1 case of low platelet count, and 1 instance of a high risk of thrombosis); these patients were referred to high-risk care; b) 59 participants from the placebo group and 46 women from the treatment group required antibiotic therapy and discontinued intervention; and c) 57 women in the placebo group and 69 women in the treatment group were nonadherent. Nearly $62 \%$ of the participants finished the trial; none of the randomised participants were lost to follow-up.

\section{Outcomes}

Four patients were excluded from the analysis: 3 from the placebo group (randomisation errors: Nugent score $<4$, two patients; gestational age miscalculation, one patient) and 1 from the treatment group (randomisation error: Nugent score $<4$ ).

Only 35 randomly assigned women, or $5 \%$, had a history of premature delivery (HPD). Tables 1 and 2 present the post-randomisation distribution of the relevant variables for the intervention and placebo groups of each stratum of women with and without a history of premature delivery (HPD; NHPD). The distribution of risk variables between the treatment groups of the nonHPD pregnant women was balanced. The distribution of risk variables among the HPD participants was balanced, except for Nugent scores $>8$, which were twice as frequent in the intervention group as in the placebo group (ns).

The outcomes were analysed according to intent-totreat and actual treatment (explanatory analysis); additional analyses were also performed, and Table 3 provides details on the corresponding denominators, i.e., which participants were included in each analysis. Of 35 HPD women, two participants from the intervention group delivered premature infants (Table 3 ). For the non-HPD stratum, the following denominators were observed: a) the rates of spontaneous deliveries at $<34$ and $<37$ weeks of gestation were less than $1 \%$ and $2.5 \%$, respectively; no infant was born at less than 30 weeks of gestation; b) the intent-to-treat relative risks of spontaneous premature birth at $<34$ and $<37$ weeks of gestation were $0.33(0.03,3.16)$ and $0.49(0.17,1.44)$, respectively, which were non-significant (ns) with $\mathrm{p}=$ 0.31 and 0.14 , (Table 3 ). Additionally, c) the corresponding actual treatment figures were zero and $0.32(0.09$, 1.19), respectively, which were ns with $\mathrm{p}=0.12$ and 0.06 (Fisher's exact test, one tail) (Table 3). The intent-totreat relative risk of spontaneous premature birth at < 37 weeks of gestation for the trial as a whole, including HPD and NHPD participants, was $0.69(0.26,1.78)$, which was ns with $\mathrm{p}=0.30$, and the corresponding actual treatment figure was $0.54(0.19,1.60)$, which was ns with $\mathrm{p}=0.20$ (Fisher's exact test, one tail).

Among the spontaneous preterm babies with $<37$ weeks of gestation, targeted neonatal complications occurred in only one infant with $<34$ weeks of gestation from the placebo group, who presented with respiratory distress syndrome and suspected early neonatal sepsis.

The recorded adverse events were minor and relatively non-specific; their frequency was low in both trial arms. The frequencies of such events in the intervention and placebo groups was as follows: nausea (5 intervention; 8 placebo), vomiting $(6 ; 4)$, diarrhoea $(3 ; 4)$, sleepiness $(0 ; 2)$, headache $(4 ; 1)$, pyrosis $(1 ; 3)$, stomach ache $(2 ; 0)$, uterine contractions $(2 ; 0)$, nausea/vomiting and headache $(1 ; 3)$, vomiting and diarrhoea $(1 ; 1)$, pruritus $(0 ; 3)$, abdominal pain and fainting $(1 ; 0)$, dizziness $(1 ; 1)$, abdominal ache $(2 ; 0)$, abdominal pain and vomiting $(1 ; 0)$, bloody diarrhoea $(1 ; 0)$, and tachycardia $(1 ; 1)$. One maternal death occurred in the placebo group; according to the Committee on Maternal Deaths of the State Health Department, the maternal death was caused by the syndrome of haemolytic anaemia, elevated liver enzymes, and a low platelet count (HELLP syndrome).

\section{Conclusions}

The efficacy of the administration of the tested probiotics at the early second trimester in preventing spontaneous preterm delivery at $<37$ weeks of gestation among women without a history of preterm delivery was not determined because the study sample was insufficient to estimate statistically significant intent-to-treat effects; additional studies are necessary to evaluate this intervention among these women.

\section{Discussion}

The findings of this trial lacked a sufficient sample size, as indicated by the $p$ values, to permit reliable inferences concerning the efficacy of the tested probiotics in preventing spontaneous premature births. However, all point estimates of relative risks for the non-HPD 
Table 1 Post-randomization distribution of relevant risk variables according to treatment group for the stratum of women without history of premature delivery (NHPD)

\begin{tabular}{|c|c|c|c|c|c|c|c|c|c|}
\hline \multirow[b]{2}{*}{ Factor } & \multicolumn{3}{|c|}{ Placebo } & \multicolumn{3}{|c|}{ Treatment } & \multicolumn{3}{|c|}{ Total } \\
\hline & Frequency & $\%$ & Mean & Frequency & $\%$ & Mean & Frequency & $\%$ & Mean \\
\hline \multicolumn{10}{|c|}{ Gestacional Age at } \\
\hline \multicolumn{10}{|c|}{ Randomization } \\
\hline$<12 w$ & 9 & $3.0 \%$ & $11 w \cdot 2 d$ & 4 & $1.3 \%$ & $11 w .4 d$ & 13 & $2.1 \%$ & $11 \mathrm{w} .2 \mathrm{~d}$ \\
\hline$(12 w-16 w)$ & 103 & $34.1 \%$ & $14 w .2 d$ & 115 & $37.5 \%$ & $14 w .3 d$ & 218 & $35.8 \%$ & $14 w .2 d$ \\
\hline$(16 w-20 w)$ & 190 & $62.8 \%$ & $18 w \cdot 6 d$ & 186 & $61.2 \%$ & $18 w .3 d$ & 376 & $61.70 \%$ & $18 \mathrm{w} .5 \mathrm{~d}$ \\
\hline$>20 w^{*}$ & 2 & $0.7 \%$ & $21 w .3 d$ & 0 & $0.0 \%$ & - & 2 & $0.3 \%$ & $21 w .3 d$ \\
\hline Total & 304 & $100.0 \%$ & $17 w .1 d$ & 305 & $100.0 \%$ & $16 w \cdot 6 d$ & 609 & $100.0 \%$ & $16 w .7 d$ \\
\hline \multicolumn{10}{|l|}{ Nugent Score } \\
\hline$<4$ & 2 & $0.7 \%$ & 2.5 & 1 & $0.3 \%$ & 1.0 & 3 & $0.5 \%$ & 2.0 \\
\hline $4-6$ & 81 & $26.6 \%$ & 5.4 & 90 & $29.5 \%$ & 5.4 & 171 & $28.1 \%$ & 5.4 \\
\hline $7-8$ & 181 & $59.5 \%$ & 7.6 & 173 & $56.7 \%$ & 7.6 & 354 & $58.5 \%$ & 7.6 \\
\hline $9-10$ & 40 & $13.2 \%$ & 9.2 & 41 & $13.4 \%$ & 9.4 & 81 & $13.3 \%$ & 9.3 \\
\hline Total & 304 & $100.0 \%$ & 7.2 & 305 & $100.0 \%$ & 7.2 & 609 & $100.0 \%$ & 7.2 \\
\hline \multicolumn{10}{|c|}{ Lag between elegible } \\
\hline \multicolumn{10}{|c|}{$\begin{array}{l}\text { Nugent score and } \\
\text { randomization }\end{array}$} \\
\hline$<=2$ weeks & 180 & $59.2 \%$ & $1 w .3 d$ & 184 & $60.3 \%$ & $1 \mathrm{w} .1 \mathrm{~d}$ & 364 & $59.8 \%$ & $1 \mathrm{w} .2 \mathrm{~d}$ \\
\hline$>2$ weeks & 124 & $40.8 \%$ & $3 w .1 d$ & 121 & $39.7 \%$ & $3 w .3 d$ & 245 & $40.2 \%$ & $3 w .2 d$ \\
\hline Total & 304 & $100.0 \%$ & $2 w .1 d$ & 305 & $100.0 \%$ & $2 \mathrm{w} .0 \mathrm{~d}$ & 609 & $100.0 \%$ & $2 \mathrm{w} .0 \mathrm{~d}$ \\
\hline \multicolumn{10}{|l|}{$\mathrm{pH}$} \\
\hline 4.5 & 90 & $29.6 \%$ & 4.50 & 81 & $26.6 \%$ & 4.50 & 171 & $28.1 \%$ & 4.50 \\
\hline 5.0 & 151 & $49.7 \%$ & 5.00 & 156 & $51.1 \%$ & 5.00 & 307 & $50.4 \%$ & 5.00 \\
\hline 5.5 or 6.0 & 63 & $20.7 \%$ & 5.52 & 68 & $22.3 \%$ & 5.54 & 131 & $21.5 \%$ & 5.53 \\
\hline Total & 304 & $100.0 \%$ & 4.96 & 305 & $100.0 \%$ & 4.99 & 609 & $100.0 \%$ & 4.97 \\
\hline \multicolumn{10}{|l|}{ Age (years) } \\
\hline$<18$ & 41 & $13.5 \%$ & 16.4 & 39 & $12.8 \%$ & 16.4 & 80 & $13.1 \%$ & 16.4 \\
\hline$>=18$ & 263 & $86.5 \%$ & 24.8 & 266 & $87.2 \%$ & 24.6 & 529 & $86.9 \%$ & 24.7 \\
\hline Total & 304 & $100.0 \%$ & 23.7 & 305 & $100.0 \%$ & 23.6 & 609 & $100.0 \%$ & 23.6 \\
\hline \multicolumn{10}{|l|}{ Height (m) } \\
\hline$<=1.55$ & 83 & $27.3 \%$ & 1.52 & 72 & $23.6 \%$ & 1.52 & 155 & $25.5 \%$ & 1.52 \\
\hline$>1.55$ & 221 & $72.7 \%$ & 1.63 & 233 & $76.4 \% 1$ & 1.63 & 454 & $74.5 \%$ & 1.63 \\
\hline Total & 304 & $100.0 \%$ & 1.60 & 305 & $100.0 \%$ & 1.60 & 609 & $100.0 \%$ & 1.60 \\
\hline \multicolumn{10}{|l|}{ Ethnicity } \\
\hline White & 105 & $34.5 \%$ & & 103 & $33.8 \%$ & & 208 & $34.2 \%$ & \\
\hline Black & 199 & $65.5 \%$ & & 200 & $65.6 \%$ & & 399 & $65.5 \%$ & \\
\hline NA & 0 & $0 \%$ & & 2 & $0.7 \%$ & & 2 & $0.3 \%$ & \\
\hline Total & 304 & $100.0 \%$ & & 305 & $100.0 \%$ & & 609 & $100.0 \%$ & \\
\hline \multicolumn{10}{|l|}{ Nulliparity } \\
\hline No & 109 & $35.9 \%$ & & 115 & $37.7 \%$ & & 224 & $36.8 \%$ & \\
\hline Yes & 195 & $64.1 \%$ & & 190 & $62.3 \%$ & & 385 & $63.2 \%$ & \\
\hline Total & 304 & $100.0 \%$ & & 305 & $100.0 \%$ & & 609 & $100.0 \%$ & \\
\hline \multicolumn{10}{|l|}{ Adherence } \\
\hline No & 107 & $35.2 \%$ & & 104 & $34.1 \%$ & & 211 & $34.6 \%$ & \\
\hline Yes & 197 & $64.8 \%$ & & 201 & $65.9 \%$ & & 398 & $65.4 \%$ & \\
\hline Total & 304 & $100.0 \%$ & & 305 & $100.0 \%$ & & 609 & $100.0 \%$ & \\
\hline
\end{tabular}

\footnotetext{
*Randomization errors: one error was related to the determination of gestational age and 3 errors were related to the assessment of the Nugent score.
} 
Table 2 Post-randomisation distribution of risk variables and adherence according to treatment group for women with a history of premature delivery (HPD)

\begin{tabular}{|c|c|c|c|c|c|c|c|c|c|c|}
\hline \multirow[b]{2}{*}{ Factor } & \multicolumn{3}{|c|}{ Placebo } & \multicolumn{3}{|c|}{ Treatment } & & \multicolumn{3}{|c|}{ Total } \\
\hline & Frequency & $\%$ & Mean & Frequency & $\%$ & Mean & & Frequency & $\%$ & Mean \\
\hline \multicolumn{11}{|c|}{ Gestacional Age at } \\
\hline \multicolumn{11}{|c|}{ Randomization } \\
\hline$<12 \mathrm{w}$ & 2 & $12.5 \%$ & $11 \mathrm{w} .6 \mathrm{~d}$ & 2 & $10.5 \%$ & $11 w .1 d$ & & 4 & $11.4 \%$ & $11 \mathrm{w} .4 \mathrm{~d}$ \\
\hline$(12 w-16 w)$ & 7 & $43.8 \%$ & $14 w .3 d$ & 7 & $36.8 \%$ & $14 w .3 d$ & & 14 & $40.0 \%$ & $14 w .3 d$ \\
\hline$(16 w-20 w)$ & 7 & $43.8 \%$ & $17 w .5 d$ & 10 & $52.6 \%$ & $19 w .4 d$ & & 17 & $48.6 \%$ & $18 w \cdot 6 d$ \\
\hline Total & 16 & $100.0 \%$ & $15 w .4 d$ & 19 & $100.0 \%$ & $16 w .5 d$ & & 35 & $100.0 \%$ & $16 \mathrm{w} .2 \mathrm{~d}$ \\
\hline \multicolumn{11}{|c|}{ Nugent Score } \\
\hline $4-6$ & 5 & $31.3 \%$ & 4.8 & 5 & $26.3 \%$ & 5.4 & & 10 & $28.6 \%$ & 5.1 \\
\hline $7-8$ & 9 & $56.3 \%$ & 7.8 & 9 & $47.4 \%$ & 7.7 & & 18 & $51.4 \%$ & 7.7 \\
\hline $9-10$ & 2 & $12.5 \%$ & 9.0 & 5 & $26.3 \%$ & 9.0 & & 7 & $20.0 \%$ & 9.0 \\
\hline Total & 16 & $100.0 \%$ & 7 & 19 & $100.0 \%$ & 7.4 & & 35 & $100.0 \%$ & 7.2 \\
\hline \multicolumn{11}{|l|}{ Height(m) } \\
\hline$<=1.55$ & 4 & $25.0 \%$ & 1.51 & 5 & $26.3 \%$ & 1.53 & 9 & $25.7 \%$ & 1.52 & \\
\hline$>1.55$ & 12 & $75.0 \%$ & 1.64 & 14 & $73.7 \%$ & 1.63 & 26 & $74.3 \%$ & 1.63 & \\
\hline Total & 16 & $100.0 \%$ & 1.61 & 19 & $100.0 \%$ & 1.60 & 35 & $100.0 \%$ & 1.60 & \\
\hline \multicolumn{11}{|l|}{ Ethnicity } \\
\hline White & 3 & $18.8 \%$ & & 5 & $26.3 \%$ & & 8 & $22.9 \%$ & & \\
\hline Black & 13 & $81.2 \%$ & & 14 & $73.7 \%$ & & 27 & $77.1 \%$ & & \\
\hline Total & 16 & $100.0 \%$ & & 19 & $100.0 \%$ & & 35 & $100.0 \%$ & & \\
\hline \multicolumn{11}{|l|}{ Adherence } \\
\hline No & 4 & $25.0 \%$ & & 7 & $36.8 \%$ & & 11 & $31.4 \%$ & & \\
\hline Yes & 12 & $75.0 \%$ & & 12 & $63.2 \%$ & & 24 & $68.6 \%$ & & \\
\hline Total & 16 & 100.05 & & 19 & $100.0 \%$ & & 35 & $100.0 \%$ & & \\
\hline
\end{tabular}

stratum, and the actual treatment analyses in particular, were less than 0.5 .

Although the number of screened women was higher than estimated, the planned sample size, based on available international and national/local information, was not attained because the attrition rates were high. The trial had to be interrupted mainly because of a lack of on-going financial support. The main sources of attrition were the higher-than-expected prevalence of clinical, vaginal $\mathrm{pH}$, and Nugent exclusion conditions. In addition, the intent-to-treat effect was likely diminished because a significant proportion of the randomised women exhibited conditions that required antibiotic therapy after the initiation of treatment (such as symptomatic vaginal discharge and urinary tract infection); this problem was more frequent in the placebo group and led to a discontinuation of the treatment. The intent-to-treat effect was also affected by a higher-thanexpected lack of adherence, which was more frequent in the intervention group. Several randomly assigned women were excluded and discontinued treatment because they suffered abortion or developed conditions for exclusion that were strongly associated with the indication of preterm delivery, such as hypertension, and were referred to high-risk care (Figure 1). However, these women were considered in the intent-to-treat analyses.

The participants were instructed to take the treatment/placebo until approximately the $24^{\text {th }}-26^{\text {th }}$ week of gestation. By this time, at the end of the second trimester, BV is less likely to occur and commonly remits; however, the main concern was to avoid delivery at $<34$ weeks, and an eventual re-infection and progression would take approximately 8 weeks to occur [9].

Three out of five women who spontaneously delivered prior to the $34^{\text {th }}$ week of gestation exhibited initial Nugent scores of 9 or 10; these scores were present in less than $15 \%$ of the total number randomised women, which is consistent with the hypothesis that BV is a risk factor for premature birth in the study population [8,37-39].

Four out of five spontaneous deliveries at $<34$ weeks of gestation were initiated with the preterm premature rupture of membranes (PPROM); only one woman was admitted for premature labour without PPROM. These 5 cases could be associated with intrauterine infection, including BV [20,40-43]. The non-PPROM case was not associated with any recorded maternal or foetal condition, other than BV, that can cause PD. Two cases of PPROM were associated with oligohydramnios; such an 
Table 3 Outcome Analyses

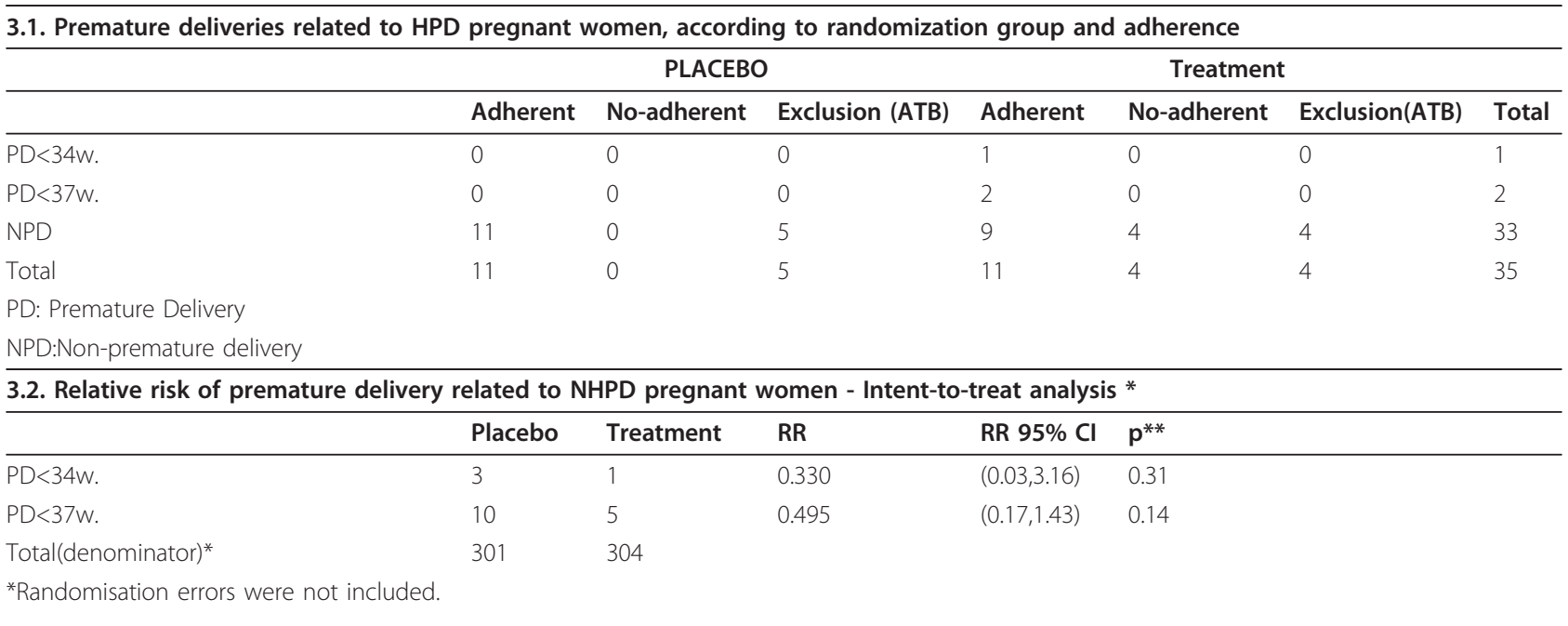

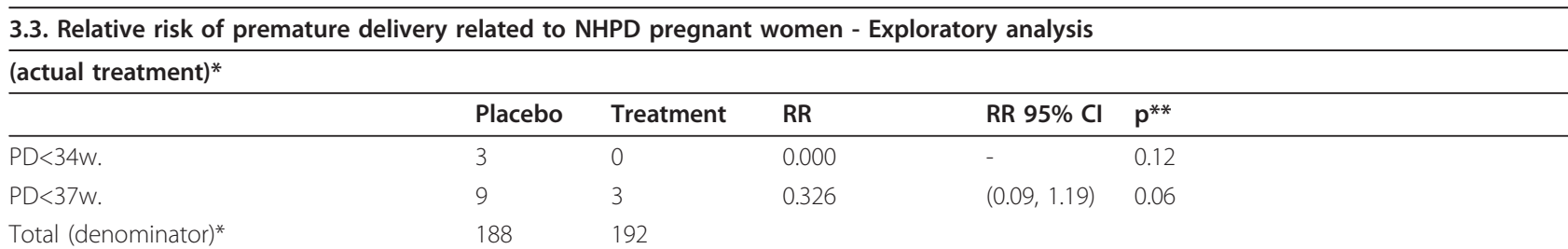

* Not included: randomization errors, those who did not receive intervention, post- randomisation exclusions, those who discontinued treatment due to antibiotics prescription, and those who were not adherent.

Additional Analysis (1)

3.4. Relative risk of premature delivery related to NHPD pregnant women

\begin{tabular}{llllll}
\hline & Placebo & Treatment & RR & RR 95\% Cl & $\mathbf{p}^{* *}$ \\
\hline PD<34w. & 3 & 1 & 0.333 & $(0.03,3.19)$ & 0.31 \\
PD<37w. & 10 & 5 & 0.500 & $(0.17,1.44)$ & 0.15 \\
Total (denominator)* & 297 & 297 & & &
\end{tabular}

*Not included: randomization errors and post-randomisation exclusions

Additional Analysis (2)

3.5. Relative risk of premature delivery related to NHPD pregnant women*

\begin{tabular}{|c|c|c|c|c|c|}
\hline & Placebo & Treatment & RR & RR 95\% Cl & $p^{* *}$ \\
\hline$P D<34 w$ & 3 & 0 & 0.000 & & 0.12 \\
\hline$P D<37 w$ & 9 & 3 & 0.323 & $(0.09,1.18)$ & 0.06 \\
\hline
\end{tabular}

* Not included: randomisation erros, those who did not receive intervention, post-randomisation exclusions, and those who discontinued treatment due to the prescription of antibiotics.

** Fisher's exact test, one tail.

association has been shown to be related to infection. One case of PPROM occurred in a woman with HPD, and the remaining case of PPROM was not associated with any recorded maternal or foetal condition, other than BV, that could cause PPROM and PD [43].

Because HPD is considered to be a major predictor of subsequent PD, including very premature births [43], women were stratified for HPD and randomly assigned with a stratum-specific randomisation list. The number of HPD women enrolled in the trial was relatively small (35 cases); the corresponding intervention arm received more severe cases of BV than the placebo arm (Table 2). Table 3a, which shows the related outcomes, has two blank cells that indicate missing data, which prevents any meaningful analysis. Furthermore, the fact that such HPD cases are generally considered especially difficult to understand and solve $[7,42]$ prompted the authors to analyse the data from the non-HPD group separately. 
The study protocol used ultrasound as the standard method for determining gestational age. Two premature infants had ultrasound-determined gestational ages of 30 $6 / 7$ and 32 4/7 weeks, which were different from the gestational ages estimated by the attending neonatologists (33 6/7 and 30 6/7 weeks, respectively). However, none of the premature infants were born before the $30^{\text {th }}$ week, which is consistent with the relatively low rate of observed morbid events and the birth weights in the study.

Neonatal records were reviewed by two research neonatologists. All 5 infants spontaneously delivered at less than 34 weeks of gestation were discharged from the hospital. Of these five cases, only one newborn was diagnosed with any of the morbid conditions under study; that infant, whose mother belonged to the placebo group and non-HPD stratum, presented with pneumonia as well as possible respiratory distress syndrome and sepsis (Table 3). Pneumonia was diagnosed based on the presence of risk factors for infection, clinical signs, and radiographic findings. Given that radiographic findings in pneumonia can be identical to those of hyaline membrane disease [44], it was not possible to dismiss HMD in the immediate postpartum period in this case. Sepsis was suspected because of an immatureto-total neutrophil ratio higher than 0.2 , although a blood culture was not positive, as required by the Vermont Oxford Network criteria. Other sources consider an immature-to-total neutrophil ratio higher than 0.2 to be an equally or more accurate criterion for early sepsis compared with a positive blood culture result [44]. The infant progressed well and did not develop bronchopulmonary dysplasia.

Interestingly, the case with delivery at $<34$ weeks of gestation, in which the Nugent score decreased from 9 to 2 by the end of the trial (normal vaginal mucosa), was an adherent woman with history of preterm delivery from the intervention arm who initiated treatment after the $20^{\text {th }}$ week of pregnancy. It has been argued that HPD is caused by chronic intrauterine infection [45]. One explanation is that lactobacilli that colonise the vagina of such women, and of women with repeated BV, produce an insufficient amount of lactic acid and other bactericidal substances $[46,47]$. In addition, the gestational age at which the vaginal infection occurs and treatment/intervention begins may interact with the maternal and foetal immune-genetic profile/response to result in birth at less than 34 weeks of gestation [48-51]. After the $20^{\text {th }}$ week of gestation, the infection may have progressed to the extent that an undesired outcome could be determined $[5,19]$.

To better understand the significance of the outcomes in the present trial, the early (early mid-trimester) and later (late mid-trimester) cervical immune-genetic profiles (i.e., selected cytokines and related genetic polymorphisms) of the randomised women are currently being analysed and may be helpful in dismissing or reinforcing the biological plausibility and, therefore, the prospects for a positive role of probiotics in the prevention of spontaneous premature births associated with bacterial vaginosis.

\section{Ethical issues}

The trial was approved by an Institutional Review Board and by the National Review Board (CONEP). The trial was monitored by an independent data monitoring committee, which performed two interim analyses of data related to the main (PD) and secondary outcomes (April 2007 and July 2008), including possible adverse events; the committee received special assistance for unblinding the group allocations. The committee did not recommend the interruption of the trial. The trial was conducted according to ICH/GCP regulations and local regulations for clinical trials.

\section{Registration}

The study was registered at the NIH register platform with identifier NCT00303082.

Sponsors: The trial was supported by grants from FIOCRUZ/Brazilian Health Ministry, SAS/Brazilian Health Ministry, and the State of Rio de Janeiro Research Foundation.

\section{List of Abbreviations}

$\mathrm{BV}$ : bacterial vaginosis; HPD: history of premature delivery,PD: premature delivery; PPROM: preterm premature rupture of membranes,RR: relative risk.

\section{Acknowledgements}

The authors thank Dr. Gregor Reid for providing the necessary batches of probiotics and placebo capsules used in the trial. They also thank the members of the monitoring committee: Luiz A.B. Camacho (Epidemiology Dept/ENSP/FIOCRUZ), Pauline L. Kale (FM/UFRJ), and Wilson Savino (IOC/ FIOCRUZ).

\section{Author details}

${ }^{1}$ Health Technology Assessment Unit, National School of Public Health, Oswaldo Cruz Foundation, Brazilian Health Ministry, Brazil, R. Leopoldo Bulhões, 1480, Rio de Janeiro, 21041-210, Brazil. ${ }^{2}$ Clinical Research Unit, Fernandes Figueira Institute, Oswaldo Cruz Foundation, Brazilian Health Ministry, Av. Rui Barbosa, 716, Rio de Janeiro, 22250-020, Brazil. ${ }^{3}$ Institute of Mathematics, Federal University in Rio de Janeiro, Av. Athos da Silveira Ramos - 149, Rio de Janeiro, 21941-909, Brazil. ${ }^{4}$ PROCEP, Pró-Cardíaco, R. General Polidoro, 142, Rio de Janeiro, 22280-003, Brazil. '5epartment of Obstetrics and Gynecology, Fernandes Figueira Institute, Oswaldo Cruz Foundation, Brazilian Health Ministry, Av. Rui Barbosa, 716, Rio de Janeiro, 22250-020, Brazil. 'Federal University in Rio de Janeiro Medical School, Av. Brigadeiro Trompowski, Rio de Janeiro, 21044-020, Brazil.

\section{Authors' contributions}

LKS and MEML contributed to the original conception of the trial. MR and MELM participated in the definition of neonatal outcomes and in the design of the neonatal data collection process. LKS, AB, FG, AAH, MRB, KGC, and MBA contributed to the design of the prenatal phase and laboratory procedures of the trial and specified most of the operational procedures. LKS and MBA estimated the study sample and participated in the 
information system design and the elaboration and execution of the data analysis. All of the authors contributed to the operational phases of the trial. All of the authors participated in drafting the manuscript and gave final approval of this version for publication.

\section{Competing interests}

The authors declare that they have no competing interests.

Received: 19 September 2011 Accepted: 8 November 2011 Published: 8 November 2011

\section{References}

1. Agency for Healthcare Research and Quality: Management of preterm labor. Evidence report/technology assessment n. 18, AHRQ public n. 01-E021 2000.

2. Leal MC, Gama SGN, Campos MR: Fatores associados à morbi-mortalidade perinatal em uma amostra de maternidades públicas e privadas do município do Rio de Janeiro, 1999-2001. Cadernos de Saúde Pública 2004, 20(Supl 1):S20-S33.

3. Campos MR, Leal MC, Souza PR Jr, Cunha CB: Consistência entre fontes de dados e confiabilidade inter-observador do estudo da morbimortalidade e atenção peri e neonatal no município do Rio de Janeiro. Cadernos de Saúde Pública 2004, 20(Supl 1):S34-S43.

4. Berkowitz GS, Prince CB, Lapinski RH: Risk factors for preterm birth subtypes. Epidemiology 1998, 9(3):279-285.

5. Goldenberg RL, Andrews WW, Hauth JC: Choriodecidual infection and preterm birth. Nutrition Reviews 2002, 60(5):S19-S25.

6. Romero R, Espinoza J, Chaiworapongsa T, Kalache K: Infections and prematurity and the role of preventive strategies. Semin Neonatol 2002, 7:259-274.

7. Goldenberg RL, lams JD, Mercer BM, Meis P, Moawad A, Das A, Copper R, Johnson F, for the national Institute of Child Health and Human Development Network: What we have learned about the predictors of preterm birth. Seminars in Perinatology 2003, 27(3):185-93.

8. Mercer BM, Goldenberg RL, Das A: The preterm prediction study: A clinical risk assessment system. Am J Obstet Gynecol 1996, 174(6):1885-1895.

9. Klebanoff MA, Hauth JC, MacPherson CA, Carey JC, Heine RP, Wapner RJ, lams JD, Moawad A, Miodovnik M, Sibai BM, van Dorsten JP, Dombrowski MP, for the National Institute for Child Health and Development Maternal Fetal Medicine Units Network: Time course of the regression of asymptomatic bacterial vaginosis in pregnancy with and without treatment. American Journal of Obstetrics and Gynecology 2004, 190(2):363-70.

10. Yoon BH, Romero R, Park JS, Kim M, Oh SY, Jun JK: The relationships among inflammatory lesions of the umbilical cord (funisitis), umbilical cord plasma interleukin 6 concentration, amniotic fluid infection, and neonatal sepsis. Am J Obstet Gynecol 2000, 183(5):1124-9.

11. Yoon BH, Romero R, Kim KS: Transactions of the nineteenth annual meeting of the society for maternal-fetal medicine. Am J Obstet Gynecol 1999, 181(4):773-9.

12. Yoon BH, Romero R, Yang SH: Interleukin-6 concentrations in umbilical cord plasma are elevated in neonates with white matter lesions associated with periventricular leukomalacia. Am J Obstet Gynecol 1996, 174(5):1433-40.

13. Gomez R, Romero R, Ghezzi F: The Fetal Inflammatory Response Syndrome. Am J Obstet Gynecol 1998, 179(1):194-202.

14. Cauci S: Vaginal Immunity in Bacterial Vaginosis. Current Infectious Disease Reports 2004, 6(6):450-6.

15. McGregor JÁ, French Jl, Richter R: Cervicovaginal microflora and pregnancy outcome: results of double-blind, placebo-controlled trial of erythromycin. Am J Obstet Gynecol 1990, 163(5 Pt 1):1580-91.

16. Hauth JC, Goldenberg RL, Andrews WW: Reduced Incidence of Preterm Delivery With Metronidazole and Erythromycin in Women with Bacterial Vaginosis. N Engl J Med 1995, 333(26):1732-6.

17. Carey JC, Klebanoff MA, Hauth JC, Hillier SL, Thom EA, Ernest JM, Heine RP, Nugent RP, Fischer ML, Leveno K, Wapner R, Varner M, Trout W, Moawad A, Sibai BM, Miodovnik M, Dombrowski M, O'Sullivan MJ, van Dorsten JP, Langer O, Roberts J: Metronidazole to prevent preterm delivery in pregnant women with asymptomatic bacterial vaginosis.
National Institute of Child Health and Human Development Network of Maternal and Fetal Medicine Units. N Engl J Med 2000, 343(8):534-40.

18. Andrews WW, Sibai BM, Thom EA, Dudley D, Ernest JM, McNellis D, Leveno K, Wapmer R, Moawad A, O'Sullivan MJ, Caritis SN, lams JD, Langer O, Miodovnik M, Dombrowski M, for the National Institute of Child Health and Human Development Maternal Fetal Medicine Units Network: Randomized clinical trial of metronidazole plus erythromycin to prevent spontaneous preterm delivery in fetal fibronectin-positive women. Obstet Gynecol 2003, 101(5):847-55.

19. Simhan HN, Caritis SN, Krohn MA, Tejada BM, Landers DV, Hillier SL: Decreased cervical proinflammatory cytokines permit subsequent upper genital tract infection during pregnancy. Am J Obstet Gynecol 2003, 189(2):560-7.

20. Romero R, Chaiworapongsa T, Kuivaniemi H, Tromp G: Bacterial Vaginosis. The inflammatory response and the preterm birth: a role for genetic epidemiology in the prevention of preterm birth. Am J Obstet Gynecol 2004, 190(6):1509-19.

21. Klein LL, Gibbs R: Use of microbial cultures and antibiotics in the prevention of infection-associated preterm birth. Am J Obstet Gynecol 2004, 190:1493-502.

22. Isolauri E, Salminen S, Ouwehand AC: Microbial-gut interactions in health and disease. Probiotics. Best Pract Res Clin Gastroenterol 2004, 18(2):299-313.

23. Vrese M, Schrezenmeir J: Probiotics and non-intestinal infectious conditions. Br J Nutr 2002, 88(Suppl 1):S59-S66.

24. Reid G, Devillard E: Probiotics for mother and child. J Clin Gastroenterol 2004, 38(Suppl 2):S94-S101

25. Reid G, Bocking A: The potential for probiotics to prevent bacterial vaginosis and preterm labor. Am J Obstet Gynecol 2003, 189(4):1202-8.

26. Reid G, Charbonneau D, Erb J, Beuerman D, Poehner R, Bruce AW: Oral use of Lactobacillus rhamnosus GR-1 and L. fermentum RC-14 significantly alters vaginal flora: randomized, placebo-controlled trial in 64 healthy women. FEMS Immunol Med Microbio 2003, 35:131-4

27. Reid G, Beuerman D, Heinemann C, Bruce AW: Probiotic Lactobacillus dose required to restore and maintain a normal vaginal flora. FEMS Immunol Med Microbio 2001, 32:37-41.

28. Reid G, Bruce AW: Selection of Lactobacillus strains for urogenital probiotic applications. J Infect Dis 2001, 183(Suppl 1):S77-80.

29. Reid G, Bruce AW, Fraser N: Oral probiotics can resolve urogenital infections. FEMS Immunol Med Microbio 2001, 30:49-52.

30. Shalev E: Ingestion of probiotics: Optional treatment of bacterial vaginosis in pregnancy. IMAJ 2002, 4:357-60.

31. Krauss-Silva, et al: Reproductive Health 2010, 7:14[http://www.reproductivehealth-journal.com/content/7/1/14].

32. Nugent RP, Krohn MA, Hillier SL: Reliability of diagnosing bacterial vaginosis is improved by a standardized method of gram stain interpretation. J Clin Microbiology 1991, 29(2):297-301.

33. Vermont Oxford Network. Database Manual of Operations. > Release 5.0. Burlington, VT 2000.

34. Altman DG, Schulz KF, Moher D, Egger M, et al: The Revised CONSORT statement for reporting randomized trials: explanation and elaboration. Ann Intern Med 2001, 134:663-694.

35. Moher D, Hopewell S, Schulz KF, Montori V, et al: CONSORT 2010 Explanation and Elaboration: Updated guidelines for reporting parallel group randomized trials. BMJ 2010, 340.

36. Schulz KF, Altman DG, Moher D, for the CONSORT Group: CONSORT 2010 Statement: Updated guidelines for reporting parallel group randomized trials. Trials 2010, 11:32.

37. Meis PJ, Goldenberg RL, Mercer B, et al: The Preterm Prediction Study: significance of vaginal infections. Am J Obst Gynecol 1995, 173:1231-5.

38. Hauth JC, Macpherson C, Carey JC, Klebanoff MA, Hillier SL, Ernest JM, Leveno KJ, Wapner R, Varner M, Trout W, Moawad A, Sibai BM, for the National Institute of Child Health and Human Development Maternal Fetal Medicine Units Network: Early pregnancy threshold vagina $\mathrm{pH}$ and gram stain scores predictive of subsequent preterm birth in asymptomatic women. Am J Obstet Gynecol 2003, 188(3):831-5.

39. Simhan HN, Caritis NS, Krohn MA, Hillier SL: Elevated Vaginal pH And Neutrophils Are Associated Strongly with Early Spontaneous Preterm Birth. Am J Obstet Gynecol 2003, 189(4):1150-4.

40. Monga M, Blanco J: Intrauterine Infection and Preterm Labor. Inf Dis Obstet Gynecol 1995, 3:37-44. 
41. Mercer BM: Preterm Premature Rupture of Membranes. Obstet Gynecol 2003, 101:178-193.

42. Romero R, Gomez R, Ghezzi F, Yoon BH, Mazor M, Edwin SS, Berry SM: A fetal systemic inflammatory response is followed by the spontaneous onset of preterm parturition. Am J Obstet and Gynecol 1998, 179(10):186-93.

43. Goldenberg R, Culhane JF, lams J, Romero R: Epidemiology and causes of preterm birth. The Lancet 2008, 371:75-84.

44. Cloherty JP, Eichenwald EC, Stark AR: Manual of Neonatal Care. Lippincott Williams \& Wilkins; Fifth edition, Philadelphia; 2004.

45. Pahlson C, Larsson PG: The ecologically wrong vaginal lactobacilli. Medical Hypotheses 1991, 36:126-130.

46. Famularo G, Pieluigi M, Coccia R, Mastroiacovo P, De Simone C: Microecology, bacterial vaginosis and probiotics: perspectives for bacteriotherapy. Med Hypotheses 2001, 56(4):421-30.

47. McLean NW, Rosenstein IJ: Characterization and selection of a Lactobacillus species to recolonize the vagina of women with recurrent bacterial vaginosis. J Med Microbiol 2000, 49:543-52.

48. lams JD, Goldenberg RL, Mercer BM, Moawad A, Das AF, Caritis SN, Miodovnik M, Menard MK, Thurnau GR, Dombrowski M, Roberts J, for the National Institute of Child Health and Human Development Maternal Fetal Medicine Units Network: The Preterm Prediction Study: Can low-risk women destined for spontaneous preterm birth be identified? Am J Obstet Gynecol 2001, 184(4):652-655.

49. Genc MR, Witkin SS, Delaney ML, Paraskevas LR, Tuomala RE, Norwitz ER, Onderdonk AB: A disproportionate increase in IL-1B over IL-1ra in the cervicovaginal secretions of pregnant women with altered vaginal microflora correlates with preterm birth. Am J Obstetrics Gynecology 2004, 190(5):1191-1197.

50. Kalinka J, Sobala W, Wasiela M, Brzezinska-Błaszczyk E: Decreased proinflammatory cytokines in cervicovaginal fluid, as measured in midgestation, are associated with preterm delivery. AJRI 2005, 54:70-76.

51. Pochard P, Gosset P, Grangette C, Andre C, Tonnel AB, Pestel J, Mercenier A: Lactic acid bacteria inhibit Th2 cytokine production by mononuclear cells from allergic patients. J Allergy Clin Immunol 2002, 110(4):617-23.

doi:10.1186/1745-6215-12-239

Cite this article as: Krauss-Silva et al:. A randomised controlled trial of probiotics for the prevention of spontaneous preterm delivery associated with bacterial vaginosis: preliminary results. Trials 2011 $12: 239$

\section{Submit your next manuscript to BioMed Central and take full advantage of:}

- Convenient online submission

- Thorough peer review

- No space constraints or color figure charges

- Immediate publication on acceptance

- Inclusion in PubMed, CAS, Scopus and Google Scholar

- Research which is freely available for redistribution

Submit your manuscript at www.biomedcentral.com/submit 